\title{
Predictive role of FAR ratio in Covid-19 patients
}

\author{
Deniz Çekiç ${ }^{1}$, Mehmet Emir Arman ${ }^{1}$, Ahmed Cihad Genç ${ }^{2}$, Kubilay İ̧sever ${ }^{3}$, ilhan \\ yıldırım $^{4}$, Ahmed Bilal Genc ${ }^{5}$, Hamad Dheir ${ }^{6}$, and Selcuk Yaylaci ${ }^{6}$ \\ ${ }^{1}$ Sakarya Universitesi Tip Fakultesi \\ ${ }^{2}$ Sakarya Training and Research Hospital \\ ${ }^{3}$ Affiliation not available \\ ${ }^{4}$ ILHAN YILDIRIM \\ ${ }^{5}$ Sakarya Universitesi \\ ${ }^{6}$ Sakarya University
}

August 10, 2021

\begin{abstract}
Objective: No effective treatment has yet been found for SARS-cov-2, which caused a pandemic outbreak in 2019. It is crucial to detect the progression of Covid-19 in patients as early as possible. Fibrinogen to albumin ratio (FAR) has been used as a new inflammatory marker. We aimed to find out whether the use of the FAR ratio as a predictor of mortality in Covid-19 patients provides clinical benefit. Materials and Methods: Data from 590 patients with Covid-19 from 15/03/2020 to 15/01/2021 in medicine wards and intensive care units (ICU) were retrospectively analyzed. Demographic data and other laboratory markers were collected from the electronic medical records. Relationship between FAR ratio was investigated between patients in the survivor/non-survivor patients. Findings: The mean FAR levels in patients who were non survivor was $24.44 \pm 30.3$ (n:272 and 11.29 6.29 (n:275) (p:0.000) in patients survivor COVID-19 infection. In ROC curve for FAR, the threshold FAR that may pose a risk for mortality was determined as 13.84 ((AUC: $0.808(0.771-0.844)$ ); $74.9 \%$ Sensitivity, $74.6 \%$ Specificity; p:0.000 )). Result: As a result of this study, increased FAR were found to be important markers in determining the mortality levels in Covid-19 patients. What is already known about FAR ratio: The fibrinogen albumin ratio is a value that has been used to determine the prognosis, especially in malignancies. [32] In a recent study 91 Covid-19 patients were analyzed 22 patients with severe disease higher FAR ratio compare to mild disaese [36] What does this article add about FAR ratio in Covid-19 patients: It has been concluded that the FAR ratio, which is used in diseases such as malignancy, hypertension, and coronary syndrome as a marker of disease progression, can be used as a mortality indicator in Covid-19
\end{abstract}

\section{Hosted file}

far ratio.docx available at https://authorea.com/users/427199/articles/533535-predictiverole-of-far-ratio-in-covid-19-patients

\section{Hosted file}

Table 1.docx available at https://authorea.com/users/427199/articles/533535-predictive-roleof-far-ratio-in-covid-19-patients

\section{Hosted file}

Figure 1.docx available at https://authorea.com/users/427199/articles/533535-predictive-roleof-far-ratio-in-covid-19-patients 